\title{
Bioquímica na escola: Educando sobre Diabetes Mellitus
}

\section{Biochemistry at school: Educating about Diabetes Mellitus}

\author{
Antônio Miguel Gomes Lima (antoniosapgomes@gmail.com) \\ Universidade Federal de Rio Grande, campus Santo Antônio da Patrulha \\ Verônica Bidinotto Brito (veronicabrito@ faccat.br) \\ Faculdades Integradas de Taquara (FACCAT)
}

Resumo: A Educação em Saúde pode ser compreendida como uma série de práticas em saúde, realizadas em determinado grupo de pessoas, a fim de melhorar e capacitar os conhecimentos a respeito da saúde humana. Tendo em vista o crescente número de pessoas com diabetes no país, foi desenvolvida uma atividade nas turmas 201 e 202 , segundos anos, da Escola Estadual de Ensino Médio Professora Gregória de Mendonça, do município de Santo Antônio Patrulha (RS, Brasil), com o objetivo de propiciar aos alunos do ensino básico que conhecessem a importância da prevenção do diabetes mellitus, e que também soubessem que existe um tratamento eficaz para a doença. Essa atividade foi realizada durante o desenvolvimento da disciplina de Bioquímica, ministrada para os cursós de jisioterapia S Enfermágem da FACCAT. Um grupo de alunos da disciplina de Bioquímica visitou a escola em dois momentos: no primeiro para aplicar um questionário para a descoberta das carências dos alunos sobre o assuno assunto, e no segundo para realizar a atividade experimental e sanar as dúvidas referentes ao tema. Osresultados demonstraram o quão importante é a inserção do ensino superior no ensino básico, para a construção do conhecimento coletivo em saúde.

Palavras-chave: Educação em Saúde; Bioquímica na Escola; Diabetes Mellitus.

\begin{abstract}
Health Education can be understood as a series of health practices, carried out in a specific group of people, in order to improve and enable knowledge about human health. In view of the growing number of people with diabetes in the country, an activity was developed in classes 201 and 202, second years, from the State High School Teacher Gregória de Mendonça, in the city of Santo Antônio Patrulha (RS, Brazil), with the objective of to provide to the basic education students to know the importance of preventing diabetes mellitus, and also to know that there is an effective treatment for the disease. This activity was carried out during the development of the Biochemistry discipline, given for the Physiotherapy and Nursing courses at FACCAT. A group of students from the Biochemistry discipline visited the school in two moments: the first to apply a questionnaire to discover the students' needs on the subject matter, and the second to carry out the experimental activity and to solve the doubts related to the theme. The results showed how important it is to insert higher education in basic education, for the construction of collective knowledge in health.
\end{abstract}

Keywords: Health Education; Biochemistry at School; Diabetes Mellitus. 


\section{INTRODUÇÃO}

Atualmente há mais de 17 milhões de pessoas vivendo com diabetes mellitus (DM) no Brasil, o que representa $11,4 \%$ da população, número que vem crescendo em nosso país e no mundo. Desde o último levantamento da Sociedade Brasileira de Diabetesfeito em 2017, o aumento de casos no Brasil foi de $31 \%$.

O tratamento para o DM pode ser medicamentoso ou não medicamentoso. O tratamento medicamentoso inclui hipoglicemiantes orais ou administração de insulina. Por súatez, no tratamente não medicamentỏs orienta-se uma reeducação alimentar, bem como a adoção de exercícios físicos diários para controlar a glicemia e prevenir as complicações associadas. Conforme POBLETE-ARO et al. (2018) o exercício favorece a transcrição do transportador de glicose (GLUT4) para a entrada de glicose nas células, reduzindo a glicose na circulação sanguínea.

Trata-se de uma doença que necessita de cuidados contínuos na alimentação, atividades físicas, monitoramento da glicemia e, quando necessário, administração de medicamentos. Nesse sentido, a educação em saúde tem um papel importante na promoção da autonomia dos sujeitos, tornando-os responsáveis e comprometidos com o próprio tratamento, além de disseminadores do conhecimento sobre essa patologia. A falta de ação educativa pode levar ao insucesso do tratamento, e corroborar para a manutenção de cuidados impróprios, levando a complicações agudas e de longo prazo (SBD, 2013).

Todos os brasileiros têm direito à vida, saúde e educação. O tema Educação em Saúde pode ser definido como um conjunto de atividades que influenciam e geram modificação de conhecimentos, atitudes e comportamentos, sempre em prol da melhoria da qualidade de vida e de saúde do indivíduo. Quando a educação em saúde é aplicada em escolas da rede pública traz a preocupação com a saúde para dentro do ensino, pois o ensino e saúde estão correlacionados.

Vanessa dos Santos (2019) diz que: "A escola é essencial na formação dos cidadãos em seus mais variados aspectos. A saúde é um desses aspectos e a escola atua, entre outros pontos: orientando os alunos para uma alimentação saudável; evitando que os alunos se exponham a situações que possam afetar sua saúde; ajudando os alunos a identificar situações de risco; promovendo a conscientização sobre a necessidade de uma vida saudável; e estimulando atitudes de promoção da saúde”. 
Portanto, se faz necessária a inserção da universidade dentro das escolas com vistas a promover um desenvolvimento mais saudável dos estudantes, o que pode ser proporcionado através de atividades de extensão. Assim, dada a importância da Educação em Saúde dentro das escolas das redes públicas e privadas, e que o DM está atingindo índices cada vez maiores da população brasileira, esta atividade visou conscientizar de forma lúdica e dinâmica uma amostra da comunidade escolar da Escola Estadual de Ensino Médio Professora Gregória de Mendonça sobre a importância de se conhecer o DM e suas complicações.

\section{DESCRIÇÃO DAS ATIVIDADES}

A escola de realização da atividade que gerou o presente relato de experiência foi a Escola Estadual de Ensino Médio Professora Gregória de Mendonça, localizada no bairro Santa Terezinha/Cidade Alta, no município de Santo Antônio da Patrulha. Foram contemplados 42 alunos do $2^{\circ}$ ano do ensino médio.

A atividade de extensão curricular foi planejada e desenvolvida como parte do plano pedagógico da disciplina de Bioquímica das Faculdades Integradas de Taquara (FACCAT), e foi orientada pela professora da disciplina, coautora, portanto desse relato. Utilizou a metodologia ativa de ensino e aprendizado "Aprendizado Baseado em Problemas" para proporcionar aprendizado aos acadêmicos e facilitar a construção do aprendizado na comunidade. Para a execução da atividade, durante a disciplina de Bioquímica, formamos um grupo de trabalho, que recebeu o nome fantasia "Mellitus". A atividade foi planejada e realizada com a supervisão e orientação da professora para a sua melhor condução. Na escola, as atividades foram realizadas em dois momentos: na primeira visita (Imagem 1) foi aplicado um questionário (Imagem 2) para levantamento das lacunas de conhecimento dos estudantes sobre o DM.
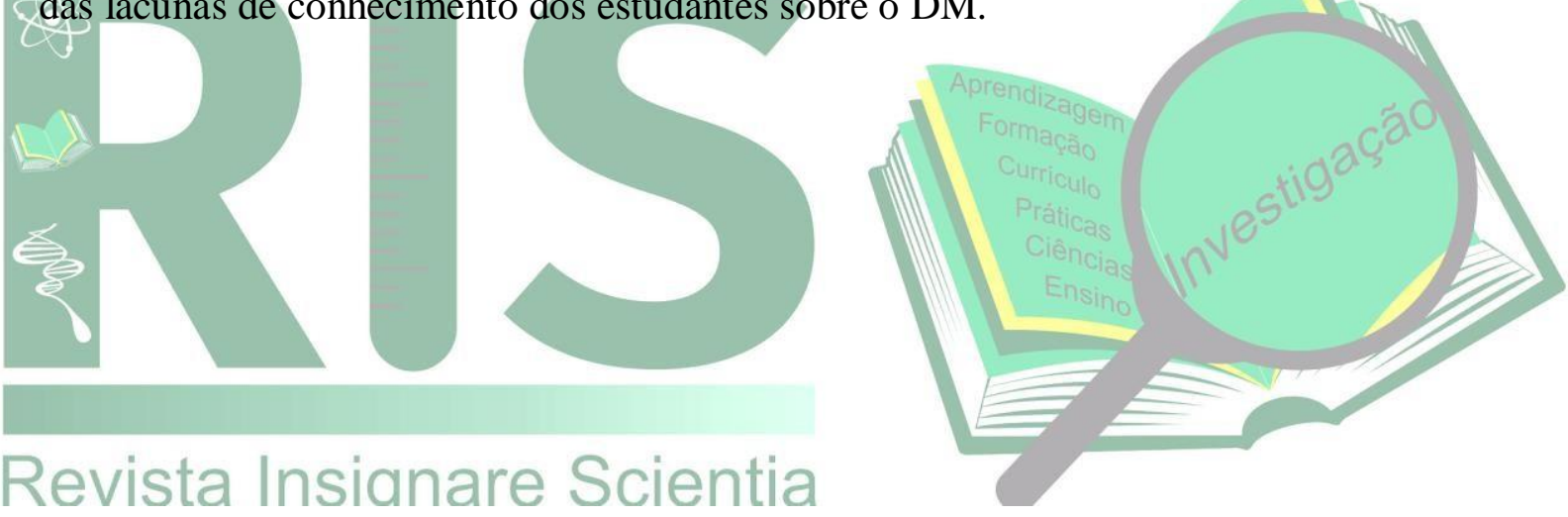


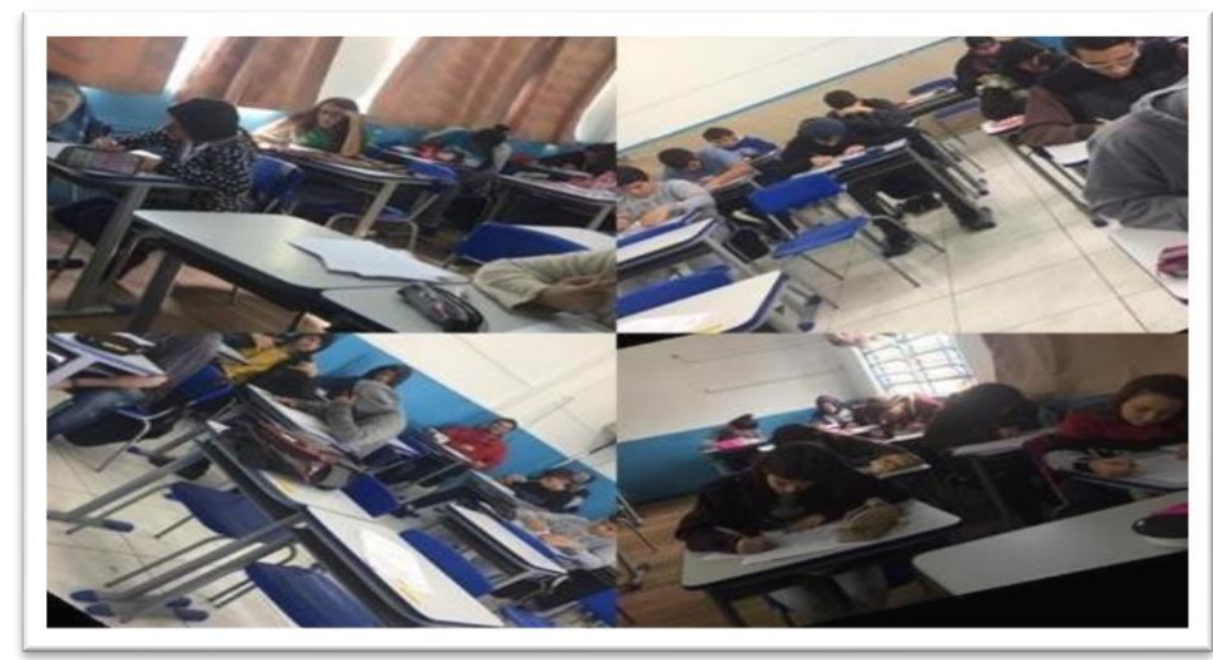

Imagem 1: Aplicação de questionário (sob documento de Autorização para uso de imagem). Fonte: Arquivo pessoal.

Após a primeira visita os dados foram avaliados e foram construídos gráficos e tabelas (Figura 1) para cada pergunta do questionário. As respostas obtidas foram classificadas em “ótimo, muito bom, bom, razoável e não sabem/não responderam” de acordo com um escore prévio.

\begin{tabular}{|c|c|c|c|}
\hline \multicolumn{4}{|c|}{ Questão 1: “O que é diabetes?” } \\
\hline Classificação da resposta & $N^{a}$ de alunos & Percentual de respostas & Representação gráfica \\
\hline Ótimo & 42 & $5 \%$ & \\
\hline Muito bom & 42 & $5 \%$ & Muito bom \\
\hline Bom & 42 & $10 \%$ & Eom \\
\hline Razoável & 42 & $40 \%$ & " Razoável \\
\hline Não sabem & 42 & $40 \%$ & \\
\hline
\end{tabular}

Figura 1: Primeira pergunta do questionário de levantamento de dados. Fonte: Arquivo pessoal.
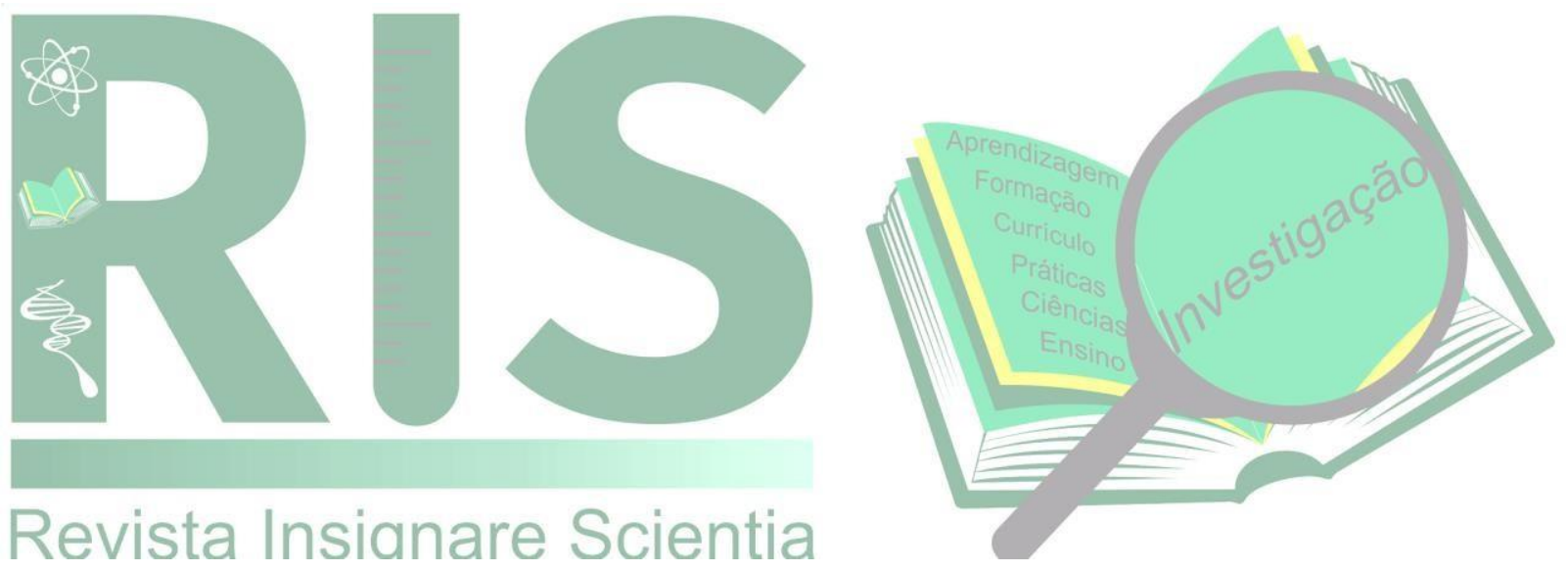

Recebido em: 30 /04/ 2020 

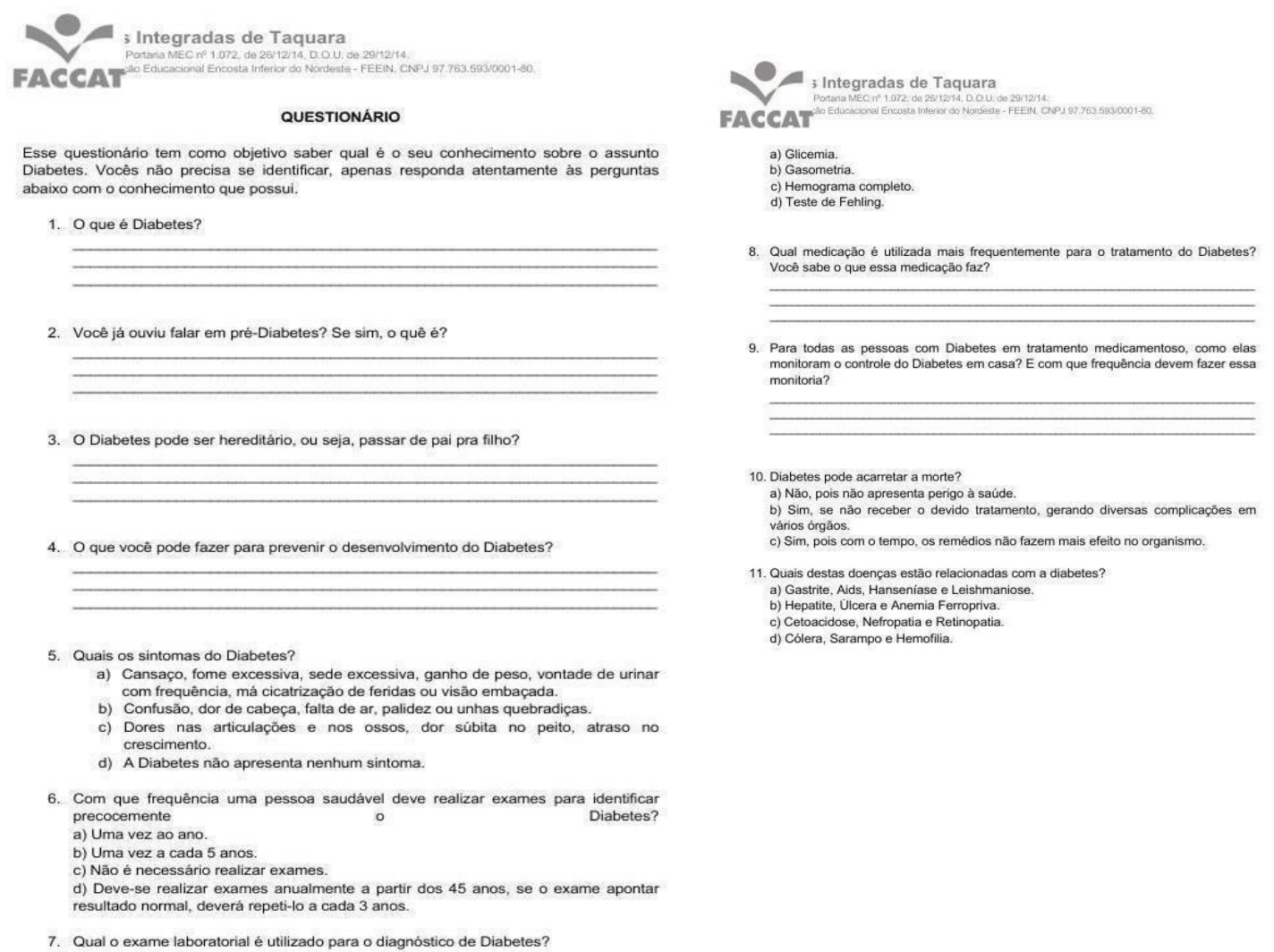

Imagem 2: Questionário aplicado para levantamento de dados na primeira visita. Fonte: Arquivo pessoal.

Questão 2: Você já ouviu falar em pré-diabetes? Se sim, o que é?

Classificação da resposta $N^{a}$ de alunos Percentual de respostas Representação gráfica

\begin{tabular}{llll}
\hline Ótimo & 42 & $0 \%$ & — Ótimo \\
Muito bom & 42 & $0 \%$ & = Muito bom \\
Bom & 42 & $0 \%$ & = Bom \\
Razoável & 42 & $9,9 \%$ & Razoável \\
Não sabem & 42 & $90,1 \%$ & - Não sabem \\
\hline
\end{tabular}

Figura 2: Segunda pergunta do questionário de levantamento de dados. Fonte: Arquivo Pessoal.

A partir das informações obtidas pelo questionário, buscou-se criar meios para facilitar a compreensão dos estudantes sobre o DM. Após díscussão com o pequeno grupo e com a professora concluímos que uma boa estratégia de educação poderia envolver: uma exposição sobre o assunto (com o uso do projetor de slides), o uso de um banner contendo os principais aspectos do diabetes e uma dinâmica em laboratório, fazendo uso de experimentos e simulações de casos clínicos. A evolução na compreensão do assunto foi realizada através da reaplicação 
do questionário. A apresentação teórica foi elaborada para que os estudantes pudessem acompanhar a abordagem e visualizar imagens que os auxiliaria no entendimento do experimento. Um banner (Imagem 3) foi confeccionado como um produto educativo, que foi posteriormente ofertado à escola, para que essa pudesse utilizá-lo em outros momentos de conscientização sobre o assunto nas demais turmas.

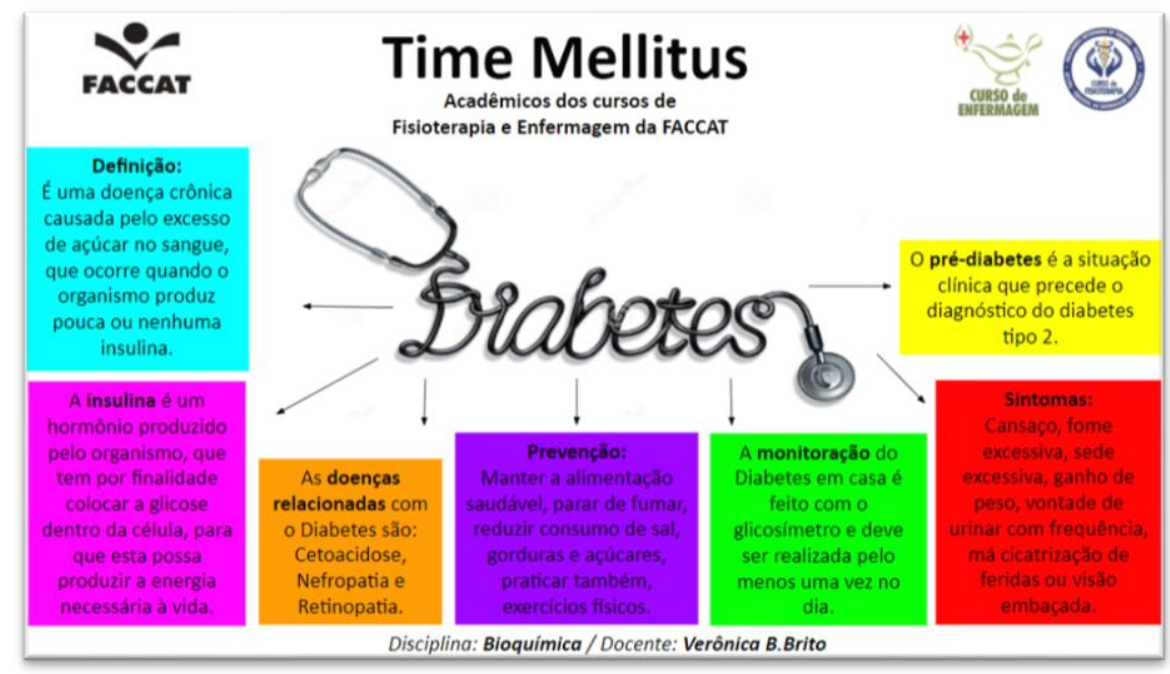

Imagem 3: Banner confeccionado para a atividade. Fonte: Arquivo pessoal.

Após, executamos um experimento prático no qual os estudantes precisavam identificar níveis elevados de glicose em um suposto material biológico e correlacionar com a possível existência de DM nos pacientes dos casos clínicos que lhes foram apresentados. A atividade experimental foi constituída por três momentos:

$1^{\circ}$ Momento: na primeira parte da atividade foi explicado aos estudantes como aconteceria a prática, aproveitando para relembrar sobre as normas e regras de segurança no laboratório da escola. Após a turma foi dividida em 5 grupos de 4 pessoas e foram sorteados os casos clínicos a serem resolvidos, sendo um caso para cada grupo. Foi-lhes entregue 3 amostras (contendo solução aquosa de glicose ou de sacarose) do suposto paciente do caso clínico, em três tubos de ensaios com tampa. Os alunos analisaram os 3 tubos. Abaixo o caso clínico $\mathrm{n}^{\circ}$, no qual os alunos deveriam experimentalmente descobrir se na suposta amostra biológica do paciente havia uma concentração elevada de glicose: "Fernanda tem 15 anos de idade é encaminhada ao pronto socorro por apresentar-se confusa, com hálito cetônico, língua e pele secașè sinais de desidratação: A paciente apresenta uma rápida e profunda ventilação, com o pH sanguíneo arterial de 7,2. 
Além disso, há presença de grupos cetona na urina. A fim de avaliar se a paciente possui diabetes, uma amostra de urina foi encaminhada ao laboratório da E. E. E. M. Prof. Gregória de Mendonça para que se faça o teste qualitativo de presença de glicose na amostra”.

$2^{\circ}$ Momento: neste momento foi desenvolvida a prática no laboratório (Imagem 4), que foi previamente organizado antes da chegada dos alunos. $\mathrm{O}$ experimento realizado utilizou conceitos da Química Orgânica e Básica para explicar que alguns carboidratos possuem um grupamento - $\mathrm{OH}$ (hidroxila) livre no carbono 1 de suas moléculas, enquanto outros não. A reação abaixo esquematiza o princípio da prova de Benedict, baseada na redução de íons $\mathrm{Cu}^{2+} \mathrm{a} \mathrm{Cu}^{+}$, com formação de precipitado vermelho ou amarelo (Imagem 5).

$$
\begin{aligned}
& \mathrm{Cu}^{2+} \stackrel{\Delta}{\longrightarrow} \mathrm{Cu}^{+} \longrightarrow \mathrm{Cu}_{2} \mathrm{O}+\mathrm{H}_{2} \mathrm{O} \\
& \text { vermelho } \\
& \text { ou }
\end{aligned}
$$

Imagem 5: Reação de redução de íons $\mathrm{Cu}^{2+} \mathrm{a} \mathrm{Cu}$, com formação de umrecipitado.

Fonte:http://www.padoho.org/bireme/index.php?option=com_content\&vie w=article\&i.

82 Os açúcares que apresentam a hidroxila livre no C-1 são bons agentes redutores. Por esse motivo a extremidade que contém a -OH passa a ser chamada de extremidade redutorae o açúcar, de açúcar redutor. A capacidade que esses compostos apresentam de reduzir íons metálicos em soluções alcalinas é um bom método de identificação desses compostos. A reação é feita em meio básico porque, nessa condição, a porcentagem de enedióis é maior. Nessa reação, o aparecimento de um precipitado de coloração vermelho-tijolo indiea que os íons $\mathrm{Cu}^{2+}$ do reagente de Benedict foram reduzidos a $\mathrm{Cu}^{+}$, indicando a presença de um açúcar redutor hà àmostra.sianare Scientia

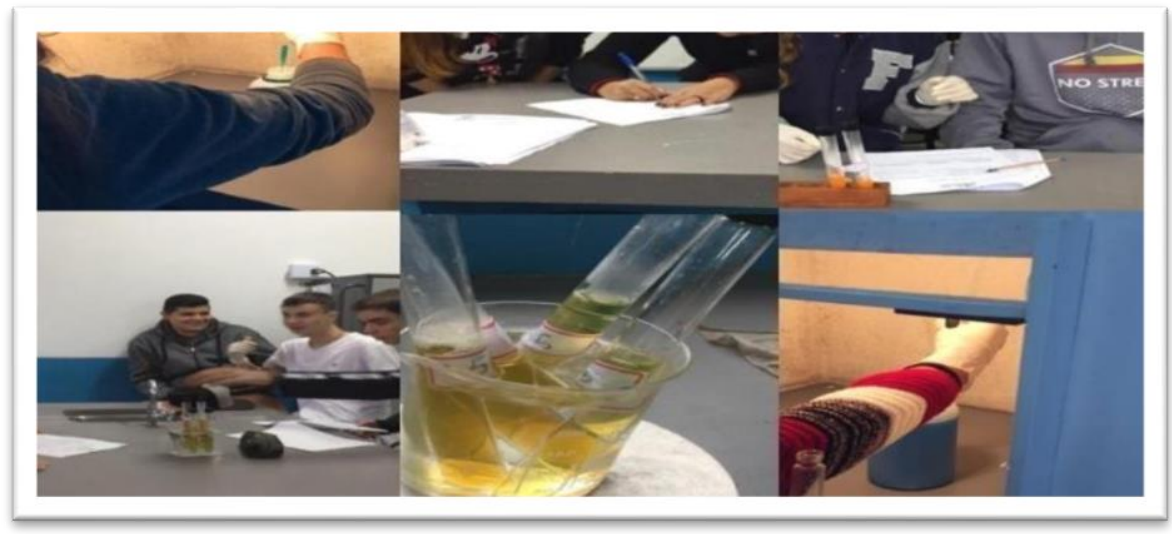

Imagem 4: Diferentes momentos da atividade experimental (sob documento de Autorização para uso de imagem). Fonte: Arquivo pessoal. 
$3^{\circ}$ Momento: nesta parte final discutimos os resultados obtidos após a análise das amostras e verificação se o paciente apresentava DM ou não. Discutimos também a importância de manter uma boa alimentação e procurar um médico quando houver sintomasde diabetes. Foi proposto que os alunos apresentassem seus casos clínicos.

Após todas as atividades serem concluídas, o questionário foi reaplicado a fim de constatar se o nível de compreensão dos estudantes havia aumentado.Para a compreensão dos resultados, foram gerados gráficos (Figuras 3 e 4), a fim de obter uma comparação de resultados em relação ao conhecimento antes da atividade (Figuras 1 e 2).

\begin{tabular}{|c|c|c|c|}
\hline \multirow{3}{*}{$\begin{array}{l}\text { Classificação da resposta } \\
\text { Ótimo }\end{array}$} & \multicolumn{2}{|c|}{ Questão 1: “O que é diabetes?” } & \multirow[b]{2}{*}{ Representação gráfica } \\
\hline & $N^{a}$ de alunos & Percentual de respostas & \\
\hline & 42 & $20 \%$ & \\
\hline Muito bom & 42 & $35 \%$ & $\mathrm{Mu}$ \\
\hline Bom & 42 & $25 \%$ & Bom \\
\hline Razoável & 42 & $10 \%$ & " Razoável \\
\hline Não sabem & 42 & $10 \%$ & Nao sabem \\
\hline
\end{tabular}

Figura 3: Primeira pergunta do questionário de levantamento de dados, após a realização daatividade. Fonte: Arquivo pessoal.

Questão 2: Você já ouviu falar em pré-diabetes? Se sim, o que é?

Classificação da resposta $N^{a}$ de alunos Percentual de respostas Representação gráfica

\begin{tabular}{llll}
\hline Ótimo & 42 & $68 \%$ & — Ótimo \\
Muito bom & 42 & $9 \%$ & — Muito bom \\
Bom & 42 & $5 \%$ & — Bom \\
Razoável & 42 & $5 \%$ & — Razoável \\
Não sabem & 42 & $5 \%$ & — Não sabem \\
\hline
\end{tabular}

Figura 4: Segunda pergunta do questionário de levantamento de dados, após a realização da atividade de extensão. Fonte: Arquivo pessoal.

A execução dessa atividade durou cerca de quatro meses de trabalho, e foi finalizada com a apresentação na FACCAT para a professora e demais colegas de turma. 


\section{ANÁLISE E DISCUSSÃO DO RELATO}

A análise dos resultados mostra que antes da visita à escola $40 \%$ dos alunos não sabiam definir o que era diabetes, enquanto que no retorno apenas $10 \%$ continuaram a não saber do que se tratava o tema, dados observados nas Figuras 1 e 3. Esse resultado demonstra que a intervenção gerou um efeito positivo sobre o entendimento do assunto. $\mathrm{O}$ mesmo foi possível observar após a análise das Figuras 2 e 4, que demonstram que o desconhecimento sobre o termo pré-diabetes reduziu de $90 \%$ para $5 \%$ após a intervenção.

Assim, constatamos que através da atividade de extensão os alunos passaram a ter mais conhecimentos sobre o DM que antes eram completamente desconhecidos por eles. Essa atividade gerou uma ação positiva para a comunidade escolar, ao possibilitar que os alunos repercutam esses conhecimentos para dentro de outras salas de aula e também de suas casas. Além disso, a doação do banner pelos acadêmicos possibilitou que outros alunos pudessem visualizá-lo e esclarecer dúvidas, podendo atingir inclusive novos alunos que frequentarem a escola.

Para o nosso grupo a atividade foi muito importante, pois foi uma forma de acadêmicos e professora de ensino superior interagir e auxiliarem a comunidade escolar de Santo Antônio da Patrulha, mais especificamente o bairro de localização da Escola (Cidade Alta/Santa Terezinha) e de moradia dos alunos, os quais ampliaram seus entendimentos sobre o tema Diabetes Mellitus, possibilitando o cuidado e prevenção da doença que é comum dentro das famílias dos estudantes. Ficou evidente a importância da extensão acadêmica, tanto no curso de Fisioterapia, quanto no curso de Enfermagem, para que haja mais compartilhamento de conhecimento. Acreditamos também que essas atividades são fundamentais nas escolas, geralmente carentes de investimento financeiro e técnico para que possam exercer plenamente sua ação educacional transformadora nos alunos, e, portanto, na sociedade. Os direitos das imagens que constam no relato foram concebidos pelos responsáveis pelos discentes. Todo o trabalho seguiu as Diretrizes da Sociedade Brasileira de Diabetes.
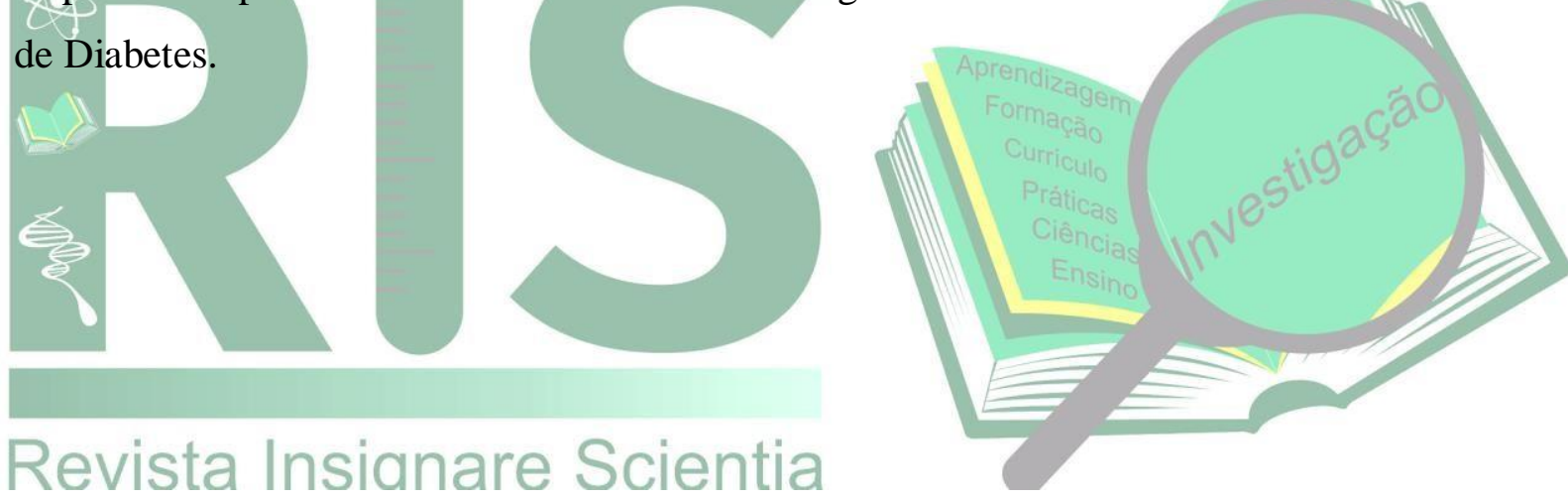


\section{CONSIDERAÇÕES FINAIS}

Nos dias atuais para falar sobre educação no Brasil é necessário falar em desigualdade e vulnerabilidade social e econômica. Em nosso país muito cedo as crianças abandonam a escola para trabalhar e muitas vezes este trabalho é escravo. E a pandemia da COVID-19 nos revelou mais uma vez a desigualdade social na educação. Uma criança na escola está adquirindo conhecimento, que muitas vezes é a respeito de saber cuidar de si e da sua família. Muitas doenças, inclusive a diabetes, podem ser prevenidas se forem ofertados cuidados essenciais para a vida humana, os quais podem ser aprendidos na escola pelas crianças que passam a gerir estes cuidados evitando algumas doenças. Isso justifica ainda mais a inserção da educação em saúde no currículo da escola,

A pedagogia libertadora de Freire pode se associar na área de educação em saúde, pois ambas fazem um diálogo, horizontalizado, contribuindo para emancipação do sujeito e para o desenvolvimento de sua saúde individual e coletiva (Falkenberg et al., 2013). Isso nos leva a pensar na importância da inserção da temática, para integrar e favorecer a comunidade escolar através de projetos sociais. Em tempos de pandemia, diversos temas são urgentes de reflexão e discussão com na comunidade, tais como saúde sanitária, biossegurança, doenças infecciosas, dentre outros. Deve-se enfatizar a importância da popularização da educação em saúde, valorizando os conhecimentos antigos e adicionando novos.

Por fim, se faz necessário destacar o tema do encontro no contexto atual "em defesa da escola, ciência e democracia" uma temática essencial na atualidade, nunca a ciência, a democracia e a escola foram tão atacadas como nos dias atuais, sobretudo pela falta de conhecimento da população em qualquer tema. A Ciência não pode ser feita de achismos. Mas talvez a pandemia da COVID-19 sirva para demonstrar à sociedade a importância da ciência, da educação e da saúde para o desenvolvimento e soberania de uma nação. Nas instituições de ensino, seja de nível fundamental, básico ou superior, o "saber" precisa ser construído. E essa "saber" se fortalece quanto mais o conhecimento é compartilhado. Mas, para isso acontecer é crucial que continuemos em uma democracia, para que o aprendizado e o conhecimento sejam livres. Liberdade hoje, amanhâ,, liberdade sempre!

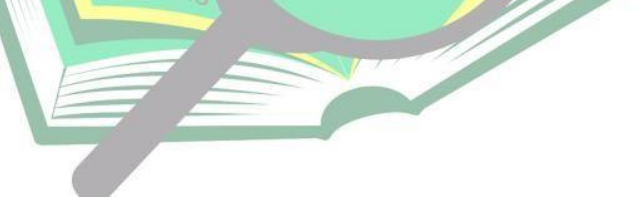




\section{AGRADECIMENTOS}

Aos meus ex-colegas de turma e graduação na FACCAT: Teodoro, C.F.M., da Silva, J.M., Fagundes, J.S., e Eninger, V.E., que, naquele momento, constituíram um grupo de trabalho na atividade proposta pela professora Brito, V.B, regente da disciplina de Bioquímica. A Brito, V.B., minha professora e orientadora nessa atividade e relato de experiência. Às Faculdades Integradas de Taquara, instituição à qual pertence a professora Brito, V.B., e onde a atividade foi planejada, e orientada. À professora Coelho, C., e à Escola Professora Gregória de Mendonça pelo acolhimento durante a realização dessa atividade. À Universidade Federal do Rio Grande, campus Santo Antônio da Patrulha, pela oportunidade de participar do evento XVI Encontro sobre Investigação na Escola.

\section{REFERÊNCIAS}

AMERICAN DIABETES ASSOCIATION. Diabetes data boklet Atlas. V.1, 2017. POBLETE-ARO, C.; RUSSELL-GUZMÁN, J; PARRA, P. et al. Exercise and oxidative stress in type 2 diabetes mellitus. Rev Med Chil; 146(3):362-372, 2018.

BRASIL. Ministério da Saúde (MS). Secretaria de Gestão do Trabalho e da Educação na Saúde. Departamento de Gestão e da Regulação do Trabalho em Saúde. Câmara de Regulação do Trabalho em Saúde. Brasília: MS; 2006.

CARVALHO, Raiana. Taxa de incidência de diabetes. Disponível em: https://portal.fiocruz.br/noticia/taxa-de-incidencia-de-diabetes-cresceu-618-nos-ultimos-10anos. Acesso em: 10 de jun de 2019.

FALKENBER el al, 2013. Educação em saúde e educação na saúde: conceitos e implicações para a saúde coletiva. Ciênc. saúde coletiva. 2014, vol.19, n.3, pp.847-852. ISSN 1413-8123. https://doi.org/10.1590/1413-81232014193.01572013.

SANTOS, dos Vanessa. Saúde na escola, disponível em: https://brasilescola.uol.com.br/saude-na-escola/. Acesso em:16 de jun de 2019.

SOCIEDADE BRASILEIRA DE DIABETES, São Paulo, SP, disponível em: https://www.diabetes.org.br/publico/. Acesso em: 15 de jun de 2019.

TRAVAIN, Silmar Antônio et al. As concepções dos alunos do Ensino Fundamental acerca do tema valor calórico dos alimentos e seus impactos na saúde. Revista Insignare Scientia. Disponível em: https://periodicos.uffs.edu.br/index.php/RIS/article/view/10601/7104. Acesso em 24 de nov de 2020. 